\title{
Specific cost modelling for secondary treatment of wastewater
}

\author{
Nikolay Makisha ${ }^{*}$ \\ Moscow State University of Civil Engineering, Yaroslavskoe shosse, 26, Moscow, 129337, Russia
}

\begin{abstract}
The article is devoted to the study of model cost indicators of wastewater treatment facilities as one of the factors for ensuring sustainable development. It is noted that the greatest contribution in terms of cost formation is provided by the stage of biological wastewater treatment. As part of the study, a techno-economic simulation was conducted to compare two technological treatment schemes: conventional activated sludge scheme in aeration reactor and secondary settling tank, and treatment by means of membrane bioreactors. In the course of technological modeling, the concentrations of pollutants after treatment were obtained and compared for each of the schemes, as well as the values of possible harm to water bodies were calculated. Within the framework of cost modeling, capital and operating costs were obtained for the two variants, and key differences in their formation were analyzed. It is noted that the classical cleaning scheme requires the construction of a larger volume of structures, while for schemes with a membrane bioreactor, a significant cost item is the purchase of the actual membrane modules, but as the system performance increases, the share of these costs decreases.
\end{abstract}

\section{Introduction}

Currently, the requirements for the quality of treated wastewater discharged into the reservoir are established by the legislation of various levels, however, in most cases, these requirements comply with the order of the Ministry of Agriculture of the Russian Federation No. 552 of December 13, 2016 [1], as a document containing the most complete list of pollutants and requirements for their discharge. This document is regularly updated and supplemented, but it can now be considered a starting point in the analysis of the use of certain technologies for wastewater treatment at sewage treatment plants.

If we talk about facilities designed for the treatment of wastewater generated in the territory of settlements of various sizes, most of them have been operated for more than a dozen years and often according to the technology provided for by the original project, which can not fit into modern requirements [2]. Thus, even without resorting to a detailed

* Corresponding author: makishana@mgsu.ru 
analysis, we can conclude that their condition is unsatisfactory and that there is an urgent need for reconstruction [3].

\section{Materials and methods}

The task of any reconstruction project is to ensure high-quality cleaning under various constraints (economic, spatial, etc.). To solve this problem, it is possible to use software packages that allow you to evaluate the possible effectiveness of using different cleaning schemes with different initial technological parameters [4-6]. In this article, we will analyze the results of modeling the application of a technological scheme based on the use of membrane bioreactors for biological wastewater treatment. The model indicators were calculated using the Capdetworks 4.0 software package. During the simulation, technological and economic indicators will be studied, as well as environmental indicators will be calculated, which include the discharge fee and the amount of damage to the water body as a result of discharge into the reservoir.

The article considers two technological schemes of cleaning. The first scheme (Fig. 1) is a traditional scheme of complete biological wastewater treatment using aeration tanksdisplacers and subsequent separation of the sludge mixture in secondary settling tanks. This scheme is quite common in many operating wastewater treatment plants. The second scheme (Fig.2) implies one of the possible options for the reconstruction of a wastewater treatment plant by using deep biological treatment in combination with membrane bioreactors for silt separation $[7,8]$.

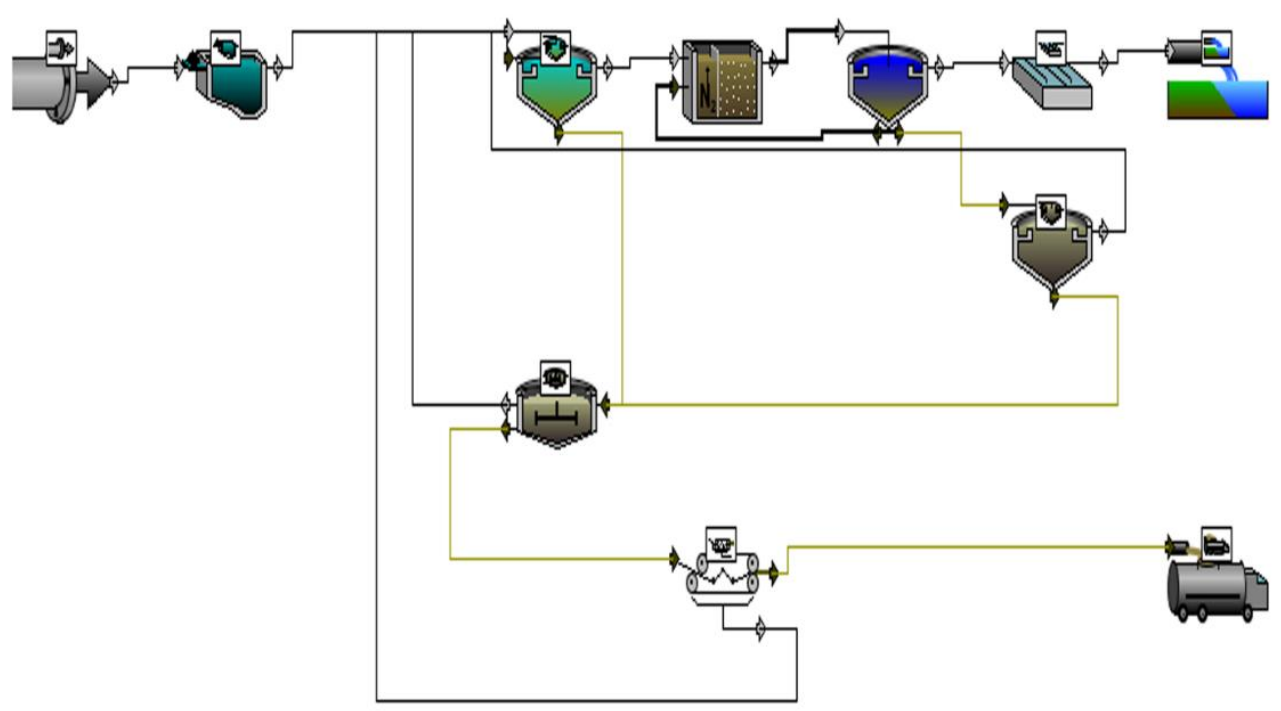

Fig. 1. Treatment scheme for option 1 


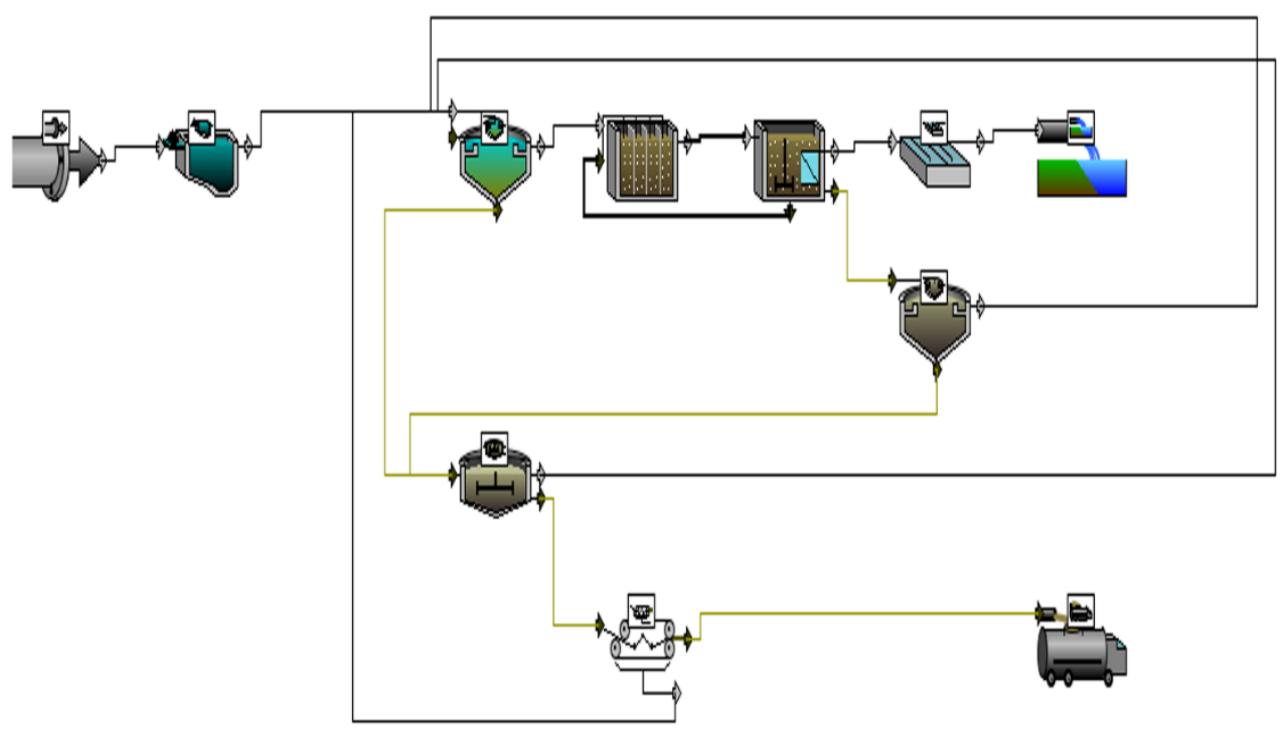

Fig. 2. Treatment scheme for option 2

The study was supposed to assess the technological features of the two schemes, the level of environmental impact, as well as to study some components of costs. At the same time, it is important to understand that any simulation studies some averaged and largely ideal conditions, but at the same time, the simulation results allow us to form a certain range of values for the processes under study.

\section{Results}

Before starting the simulation, the main parameters typical for the operation of both technological variants were determined (Table 1).

Table 1. Initial parameters

\begin{tabular}{|c|c|c|}
\hline Indicator & Option 1 & Option 2 \\
\hline Flow $\mathrm{Q}_{\text {daily }}\left[\mathrm{m}^{3} / \mathrm{day}\right]$ & 10000 & 10000 \\
\hline Flow $\mathrm{Q}_{\text {mid.hour }}\left[\mathrm{m}^{3} / \mathrm{h}\right]$ & 417 & 417 \\
\hline Coefficient of irrugularity $[8]$ & 1,51 & 1,51 \\
\hline Flow $\mathrm{Q}_{\max . \text { hour }}\left[\mathrm{m}^{3} / \mathrm{h}\right]$ & 667 & 667 \\
\hline MLSS [g $/ \mathrm{L}]$ & 3 & 7 \\
\hline Sludge retention time [day] & 10 & 20 \\
\hline Aeration rate $\left[\mathrm{m}^{3} / \mathrm{m}^{3}\right]$ & 7 & 12 \\
\hline Flux $\left[\mathrm{L} / \mathrm{h}^{*} \mathrm{~m}^{2}\right]$ & - & 20 \\
\hline Membrane density $\left[\mathrm{m}^{2} / \mathrm{m}^{3}\right]$ & - & 130 \\
\hline
\end{tabular}

Before starting the simulation, the initial concentrations of pollutants were determined by the main indicators (Table 2). The initial concentrations generally correspond to the average values typical for urban wastewater entering the treatment. Table 2 also shows the concentrations after purification and the standard values established [1] for each of the indicators. 
Table 2. Pollution concentrations in the simulation

\begin{tabular}{|c|c|c|c|c|}
\hline \multirow{2}{*}{ Indicator } & \multirow{2}{*}{ Influent } & \multicolumn{2}{|c|}{ Effluent } & \multirow[t]{2}{*}{ Limits [1] } \\
\hline & & Option 1 & Option 2 & \\
\hline $\mathrm{BOD}_{5}\left[\mathrm{mgO}_{2} / \mathrm{L}\right]$ & 220 & 4,3 & 1,6 & 2,1 \\
\hline TSS [mg/L] & 220 & 10 & 3,0 & back $+0,25$ \\
\hline $\mathrm{N}-\mathrm{NH}_{4}[\mathrm{mg} / \mathrm{L}]$ & 30 & 21,5 & 0,33 & 0,4 \\
\hline $\mathrm{N}-\mathrm{NO}_{2}[\mathrm{mg} / \mathrm{L}]$ & - & 1,0 & 0,015 & 0,02 \\
\hline $\mathrm{N}-\mathrm{NO}_{3}[\mathrm{mg} / \mathrm{L}]$ & - & 2 & 7,2 & 9 \\
\hline $\mathrm{P}-\mathrm{PO}_{4}[\mathrm{mg} / \mathrm{L}]$ & 10 & 7 & 0,05 & 0,2 \\
\hline
\end{tabular}

conventionally, the classical scheme, which in principle is aimed at removing primarily organic pollutants and suspended substances, is not able to provide the required quality of purification for biogenic elements. However, the purpose of the study was not to confirm this. It is much more important to understand how the key technological and cost indicators will differ when upgrading the existing scheme. From this point of view, the content of pollutants in treated wastewater is both the result of modeling and a kind of initial data for further calculations. In other words, knowing these values, you can proceed to the calculations of further indicators.

For example, based on Table 2 and using the methodology [10], it is possible to estimate the approximate amount of damage caused to the reservoir by discharged wastewater, which will amount to about 160 million rubles per year when using the old wastewater treatment scheme. In addition, according to the method [11], it is possible to determine the annual fee for the discharge of wastewater that does not meet the requirements of the regulations, which for the current conditions will be approximately 5.1 million rubles.

Table 3 shows the areas and volumes of structures calculated during the simulation. If for option 1 , the values of the volumes and the area of the location of individual structures were obtained - the aeration tank (A) and the secondary sump (B), then for option 2, the membrane modules (MBR) are integrated into the volume of the aeration tank, that is, in the first case, two structures are considered, in the second - only one.

Table 3. Area and volume of secondary treatment facilities

\begin{tabular}{|c|c|c|c|c|c|c|}
\hline \multirow{2}{*}{$\begin{array}{c}\text { Daily flow } \\
{\left[\mathrm{m}^{3} / \text { day }\right]}\end{array}$} & \multicolumn{3}{|c|}{ Area, $^{2}$} & \multicolumn{3}{c|}{ Volume, $^{3}$} \\
\cline { 2 - 7 } & Bio & ST & Bio+MBR & Bio & ST & Bption 2 \\
\hline 10000 & 420 & 500 & 520 & 2100 & 1030 & 2600 \\
\hline
\end{tabular}

As it can be seen, the volume of aeration tanks for option 1 is less by about $20 \%$. It is important to note that the volumes directly depend on the technological parameters, so in real conditions, the differences in volumes may be different or not at all. Secondary settling tanks require additional volumes, but this is important in the case of new construction. If we are talking about the modernization of existing facilities with the use of ICBMs, then the released volumes can be used for other technological needs.

As already mentioned, the volume savings in option 2 are achieved through the use of membrane modules, the purchase of which and further operation require impressive costs. If we start from the values of the maximum hourly flow rate and the specific flow rate of water through the surface of the membrane presented in Table 1, and also take into account the cost of $1 \mathrm{~m} 2$, which is approximately 4,000 RUR for membranes, then the cost of purchasing only membranes (without other necessary equipment) will amount to 133.2 million rubles. At the same time, the membranes themselves require replacement every 7 - 
10 years under normal operating conditions, which must be provided by qualified personnel. It is important to add that membrane technologies are becoming more widespread recently, which inevitably leads to lower costs for their application and increased availability.

If to consider operating costs, they will also increase significantly in the case of membranes application (Table 4).

Table 4. Energy performance of the facilities

\begin{tabular}{|l|l|l|}
\hline Indicator & $\begin{array}{l}\text { Option } \\
1\end{array}$ & $\begin{array}{l}\text { Option } \\
2\end{array}$ \\
\hline Energy consumption for secondary treatment $[\mathrm{MWh} /$ day $]$ & 469,5 & 1813 \\
\hline WWTP Energy consumption $[\mathrm{MWh} /$ day $]$ & 768 & 2113 \\
\hline Specific energy consumption $\left[\mathrm{kWh} / \mathrm{m}^{3}\right]$ & 0,21 & 0,56 \\
\hline Required power $[\mathrm{kW}]$ & 87,5 & 233,3 \\
\hline
\end{tabular}

As can be seen, the electricity requirements for the secondary treatment unit increase almost three times when using the technological scheme according to option 2 due to the fact that in addition to the electricity consumption for aeration of the sludge mixture, recirculation of the return activated sludge and pumping out excess activated sludge, a significant amount of electricity is required for pumping out the entire flow of the treated water by vacuum pumps, as well as the cost of air supply for blowing the membranes.

\section{Conclusions}

1. As a result of the simulation conducted to review the technological schemes of wastewater treatment before and after reconstruction, it was possible to obtain approximate quantitative indicators of the work of structures that generally correspond to real objects, that is, the simulation results can be regarded as close to practice.

2. The use of membrane bioreactors allows ensuring the quality of cleaning that meets the current regulatory requirements (which significantly reduces the amount of possible environmental charges), but is costly in terms of both capital and operating costs, for example, during the simulation, an increase in the specific cost of electricity, for example, by about 2.5 times $\left(0.21\right.$ and $\left.0.56 \mathrm{kWh} / \mathrm{m}^{3}\right)$, but these data require validation in real conditions.

3. The widespread adoption of membrane technologies is gradually reducing the cost of membranes, which will certainly increase their availability in the future.

\section{References}

1. Order of the Ministry of agriculture of the Russian Federation No. 552 dated December 13, 2016 "On approval of water quality standards for water bodies of fisheries significance, including standards for maximum permissible concentrations of harmful substances in the waters of water bodies of fisheries significance"

2. Doronin S.V., Harkin S.V. Vodoochistka. Journal of Water purification. Water preparation. Water supply, 3, 22-35 (2017)

3. ITS 10-2019. Wastewater treatment using centralized water disposal systems in settlements and urban districts

4. Mao X., Myavagh P.H., Lotfikatouli S., Hsiao B.S., Walker H.W. J. of Environmental Eng., 146, 03120002 (2020) 
5. Blandin G., Gautier C., Sauchelli Toran M., Monclús H., Rodriguez-Roda I., Comas J. Chem. Eng. J., 339, 268-277 (2018)

6. Kulakov A.A., Lebedeva E.A. J. of. Water supply and Sewerage, 4, 60-67 (2011)

7. Mannina G., Ni B.-J., Ferreira Rebouças T., Cosenza A., Olsson G., Bioresource Technology, 302, 122824 (2020)

8. Poupyrev E.I. Construction and reconstruction, 4 (60), 173-182 (2015)

9. SP 32.13330.2012. Sewerage. Outdoor networks and structures. Updated version of SNiP 2.04.03-85]

10. Order of the Ministry of natural resources of the Russian Federation dated April 13, 2009 No. 87 "On approval of the Methodology for calculating the amount of damage caused to water bodies due to violations of water legislation"

11. Resolution of the government of the Russian Federation No. 913 of September 13, 2016 "On payment rates for negative environmental impact and additional coefficients»

All tests were carried out using research equipment of The Head Regional Shared Research Facilities of the Moscow State University of Civil Engineering. 